\title{
Deposition and Strain of the Cuticle of Developing European Plum Fruit
}

\author{
Moritz Knoche ${ }^{1,2}$ and Stefanie Peschel \\ Institute for Agronomy and Crop Science, Department of Horticulture, Martin-Luther-University \\ of Halle-Wittenberg, D-06099 Halle (Saale), Germany
}

\begin{abstract}
AdDitional INDEX words. Cutin, microcrack, fruit growth, stomata, wax, Prunus domestica
Abstract. Time courses of change in 1) fruit mass and surface area, 2) deposition of the cuticular membrane (CM), 3) strain of the CM, and 4) formation of microcracks in the CM of developing fruit of european plum (Prunus domestica L. ssp. domestica) were established. Fruit mass, fruit surface area, and CM mass per fruit increased between 50 and 133 days after full bloom (DAFB). Rates of CM deposition were higher during early stage III (50-71 DAFB) when amounts of wax and cutin per fruit increased, resulting in an increase in CM thickness from 3.1 to $5.9 \mathrm{~g} \cdot \mathrm{m}^{-2}$. Thereafter, cutin deposition ceased and CM thickness decreased to $4.7 \mathrm{~g} \cdot \mathrm{m}^{-2}$ at $133 \mathrm{DAFB}$. Percentage strain, determined on enzymatically isolated CM disks using image analysis, slightly decreased from $12.0 \%$ at 50 DAFB to $4.5 \%$ at $71 \mathrm{DAFB}$, but increased thereafter, averaging about $40 \%$ at $133 \mathrm{DAFB}$. The breakpoint in the time course of strain at 71 DAFB corresponded to the change in rate of cutin deposition. Frequency of microscopic cracks in the CM was closely related to strain of the $\mathrm{CM}$ across different developmental stages within a cultivar (pedicel end and cheek region) and across different cultivars at maturity. There was little change in microscopic cracking up to $\approx \mathbf{2 0} \%$ strain. However, microcracks markedly increased when strain exceeded $20 \%$. Most microcracks $(91.0 \% \pm 3.7 \%$ at 133 DAFB) were associated with stomata. These data indicate that a mismatch between surface area expansion of the growing fruit and cutin deposition caused strain and subsequent microcracking of the CM of developing plum.
\end{abstract}

The cuticular membrane $(\mathrm{CM})$ covers all aboveground, primary surfaces of terrestrial plants. It serves as a protective barrier against water loss, infection with pathogens, and mechanical damage. Maintaining these functions throughout development requires an intact $\mathrm{CM}$. This is a particular challenge for the $\mathrm{CM}$ on fruit that often are characterized by continuous surface expansion until maturity. Recent investigations in sweet cherry (Prunus avium L.) established that the CM is markedly strained during stage III ["final swell" (Lilleland and Newsome, 1934)] of fruit development, which is characterized by a rapid increase in fruit mass and, hence, surface area in the absence of CM deposition (Knoche et al., 2004). Furthermore, the resulting strain of the CM is closely and positively related to frequency and severity of microscopic cracks in the CM (Knoche and Peschel, 2006). Cracks impair the barrier function of the $\mathrm{CM}$ and serve as entry ports for fruit rot pathogens, including Botrytis cinerea Pers. and Monilinia laxa (Aderh. \& Ruhland) Honey 1945 (Borve et al., 2000).

European plum belongs to the stone fruit group and its drupe has the same double-sigmoidal growth pattern as that of the sweet cherry. It therefore may be hypothesized that in plum, $\mathrm{CM}$ deposition does not keep pace with fruit surface expansion and that this causes strain and microcracking of the CM. The objective of our study was to test this hypothesis. We focused on time courses of change in 1) fruit mass, 2) deposition of the

Received for publication 21 Feb. 2007. Accepted for publication 22 June 2007. This research was funded in part by grants from the Deutsche Forschungsgemeinschaft.

We thank Philipp Moser and Kurt Ehm for providing fruit samples; Steffen Both, Matthias Hinz, and Ruth Richter for technical assistance; and Eckhard Grimm for critical comments on an earlier version of this manuscript.

${ }^{1}$ Current address: Institute for Biological Production Systems, Fruit Science Division, Leibniz University of Hannover, Herrenhäuser Straße 2, 30419 Hannover.

${ }^{2}$ Corresponding author. E-mail: moritz.knoche@obst.uni-hannover.de.
$\mathrm{CM}, 3$ ) strain, and 4) formation of microcracks in the $\mathrm{CM}$ of developing fruit of european plum.

\section{Materials and Methods}

Plant material. Fruit of european plum cultivars Auerbacher, Cacaks Fruchtbare, Elena, President, Valjevka, and Verity ('Auerbacher' grafted on 'Myrobalane' rootstocks; all others grafted on 'GF 655') were obtained from commercial orchards located near Eisleben, Germany (lat. $51^{\circ} 31^{\prime} \mathrm{N}$, long. $\left.11^{\circ} 44^{\prime} \mathrm{E}\right)$. Fruit were harvested at commercial maturity except for 'Valjevka', which was sampled weekly or at 2-week intervals between 50 and $133 \mathrm{~d}$ after full bloom (DAFB). Fruit were selected for uniformity of development (based on color and size) and freedom from visual defects and were processed fresh.

Fruit development. Fruit mass and surface area were monitored in developing 'Valjevka' fruit. Surface area $\left(A_{\text {fruit }}\right)$ was calculated from the polar radius ( $a$, equivalent to fruit height divided by two) and equatorial radius (b), assuming the shape of a prolate ellipsoid:

$$
A_{\text {fruit }}=2 \pi b\left[\left(b+\frac{a^{2}}{\sqrt{a^{2}-b^{2}}}\right) \cdot \frac{\operatorname{ar} \sin \left(\sqrt{a^{2}-b^{2}}\right)}{a}\right]
$$

Fruit height and equatorial diameter were determined on 20 fruit using an electronic caliper. Osmotic potential of fruit juice extracted from the mesocarp was determined by vapor pressure osmometry (model 5520; Wescor, Logan, UT). Juice samples from five individual fruit were pooled for a single observation, and determinations were carried out on five independent replicates.

Cuticular membrane isolation. Exocarp segments comprising cuticle, epidermal and hypodermal cell layers, and 
adhering mesocarp tissue were excised from the cheek region of plum using a cork borer (i.d., $8.9 \mathrm{~mm}$ ). Cuticular membranes were isolated from exocarp segments as described previously (Knoche and Peschel, 2006). Briefly, exocarp segments were incubated in $50 \mathrm{~mm}$ citric acid buffer solution $(\mathrm{pH}, 4.0)$ containing pectinase $\left[90 \mathrm{~mL} \cdot \mathrm{L}^{-1}\right.$ (Panzym Super E flüssig; Novozymes AG, Dittingen, Switzerland)] and cellulase [5 $\mathrm{mL} \cdot \mathrm{L}^{-1}$ (Celluclast; Novozymes, Bagdsvaerd, Denmark)]. $\mathrm{NaN}_{3}$ was added at a final concentration of $30 \mathrm{~mm}$ to prevent microbial activity. After separation and isolation, CM were desorbed in deionized water and dried. Soluble cuticular lipids were quantified by batch extracting CMs with 10 consecutive changes of $0.5 \mathrm{~h}$ each in $\mathrm{CHCl}_{3} /$ methanol $(1: 1, \mathrm{v} / \mathrm{v})$ at $80^{\circ} \mathrm{C}$. Extracted CMs are referred to as dewaxed CM (DCM). Mass of CM or DCM was determined gravimetrically on a minimum of $15 \mathrm{CM} / \mathrm{DCM}$ disks per replicate, with a total of five replications.

Strain of CM disks was quantified as described previously using image analysis (Knoche et al., 2004). Digitized calibrated images of individual $\mathrm{CM}$ disks were prepared at $\times 4$ (MZ6 microscope; Leica Mikrosysteme GmbH, Bensheim, Germany) using a video camera (Hitachi Denshi Europa GmbH, Rodgau, Germany), the perimeter of the CM disk traced, and the CM area quantified (analySIS 3.0 software package; Soft Imaging System GmbH, Münster, Germany). Strain $[\varepsilon(\%)]$ was calculated according to Eq. 2, where $A$ represents the surface area of the $\mathrm{CM}$ covered on the fruit before excision and $A_{O}$ is the area of the relaxed CM after isolation:

$$
\varepsilon=\frac{A-A_{O}}{A_{O}} \cdot 100
$$

Because the diameter of the cork borer was small relative to the size of the fruit, the cross-sectional area of the cork borer was used as an estimate for $A$. Numbers of replications were 5 and 10 for quantifying $\mathrm{CM}$ mass per unit area and $\mathrm{CM}$ strain respectively.

Monitoring Microscopic CRACKS IN THE CUTICle OF DEVELOPING FRUIT. Formation of microscopic cracks, subsequently referred to as microcracks, was monitored in developing 'Valjevka' fruit and in mature fruit of selected plum cultivars using the procedure by Peschel and Knoche (2005). These microcracks are limited to the $\mathrm{CM}$, do not extend into the epi- and hypodermal cell layers or the mesocarp of the fruit, and are only detected by microscopy (Glenn and Poovaiah, 1989; Peschel and Knoche, 2005). Uniformly developed fruit free of visual defects were incubated for $2 \mathrm{~min}$ at ambient temperature in a solution containing the fluorescent tracer acridine orange at $0.1 \%$ and the silicone surfactant Silwet L-77 (Witco, Düsseldorf, Germany) in $50 \mathrm{~mm}$ citric acid buffer at a $\mathrm{pH}$ of 6.5. This solution infiltrated microcracks in the CM. Subsequently, fruit were blotted and exocarp segments excised by razor blade from cheek and pedicel regions. Exocarp segments were transferred to the stage of a fluorescence microscope (model BX-60; Olympus, Hamburg, Germany) and viewed at $\times 100$ (filter module U-MWU, 330-385 nm excitation wavelength, $420 \mathrm{~nm}$ emission wavelength; Olympus). Five randomly selected areas $\left(621 \times 468 \mu \mathrm{m}^{2}\right)$ per exocarp segment of a total of 20 fruit per sampling date, region, and cultivar were inspected for microcracks in the CM. Microcracking was quantified using the rating scheme previously adopted for sweet cherry fruit (see Fig. 1 in Peschel and Knoche, 2005), where 0 is surface without

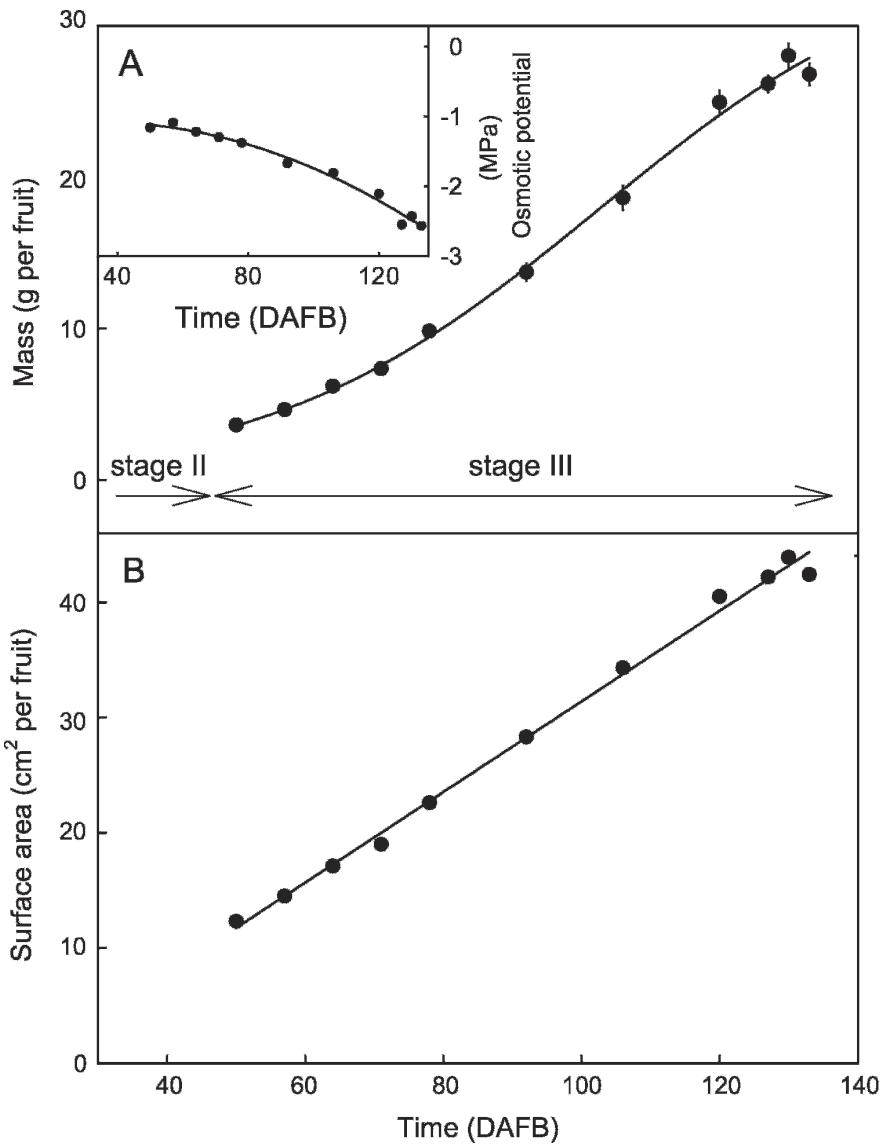

Fig. 1. (A, B) Time course of change in fruit mass (A), osmotic potential (A, inset), and fruit surface area (B) of developing 'Valjevka' european plum. $\mathrm{X}$-axis scale in days after full bloom (DAFB).

cracks, 1 is a single microcrack shorter than the longest dimension of adjacent epidermal cells, 2 is more than one microcrack shorter than the longest dimension of adjacent epidermal cells or single microcrack longer than the longest dimension of adjacent epidermal cells, 3 is less than eight microcracks longer than the longest dimension of adjacent epidermal cells, and 4 is eight or more microcracks longer than the longest dimension of adjacent epidermal cells. Arithmetic means and SES of means were calculated.

Data ANAlysis AND PResentation. Data are presented as means and SES of means. Linear and nonlinear regression and correlation analyses were carried out on treatment means using SAS (version 9.1; SAS Institute, Cary, NC).

\section{Results}

Fruit mass increased and osmotic potential $\left(\psi_{\mathrm{S}}\right)$ of the mesocarp decreased with time between 50 and 133 DAFB (Fig. 1A). The observed change in fruit mass with time corresponded to stage III of stone fruit development. Fruit mass and $\psi_{\mathrm{S}}$ were closely related $(r=-0.98, P \leq 0.0001)$. Fruit surface area increased nearly linearly with time, indicating that the rate of surface area expansion remained constant between 50 and 133 DAFB $\left(0.39 \pm 0.01 \mathrm{~cm}^{2} \cdot \mathrm{d}^{-1} ; r^{2}=0.99, P \leq 0.0001\right.$; Fig. 1B).

The mass of $\mathrm{CM}$ per unit fruit surface area changed in a biphasic pattern with time (Fig. 2A). Between 50 and 71 DAFB, 


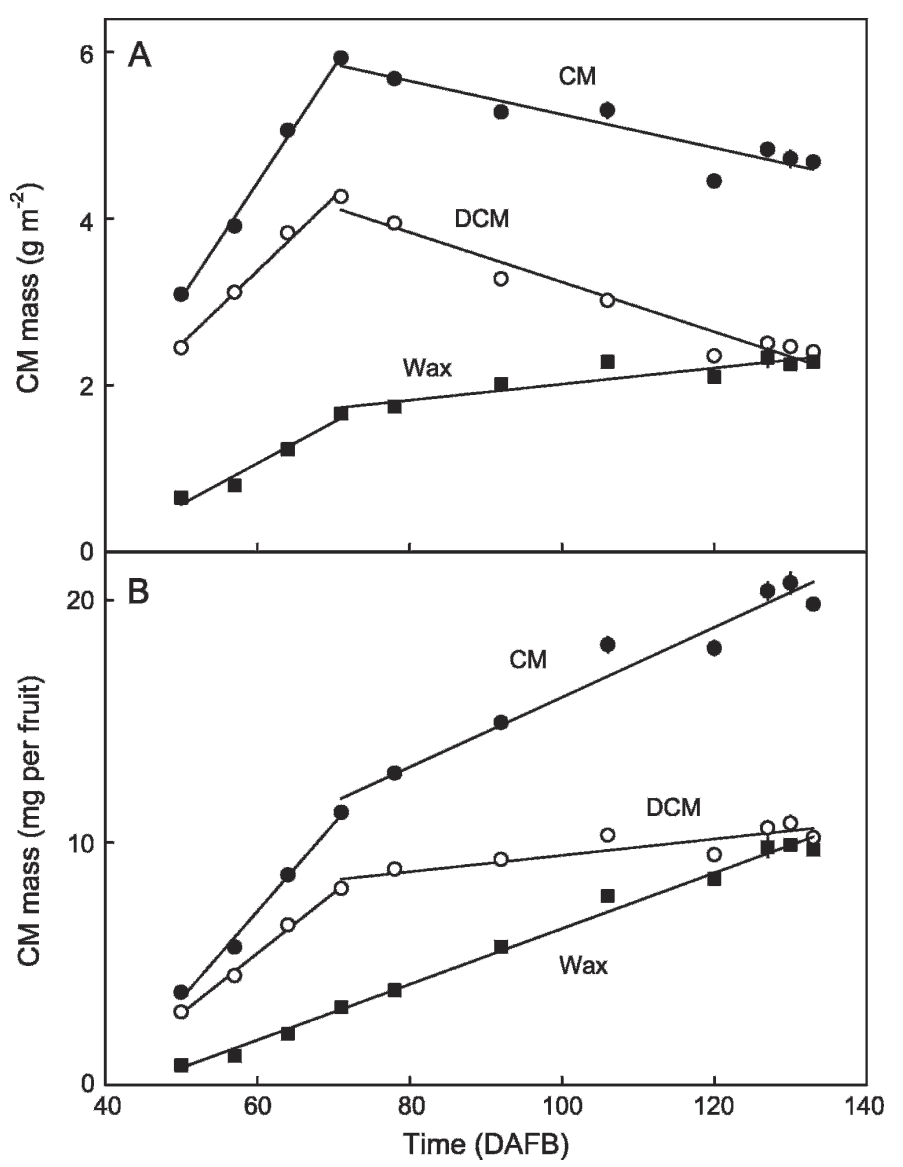

Fig. 2. (A, B) Time course of change in mass of cuticular membrane (CM), dewaxed CM (DCM), and wax in developing 'Valjevka' european plum. Mass of CM, DCM, and wax was expressed as mass per unit fruit surface area (A) and mass per fruit (B). X-axis scale in days after full bloom (DAFB).

$\mathrm{CM}$ mass per unit area increased from 3.1 to $5.9 \mathrm{~g} \cdot \mathrm{m}^{-2}$ (equivalent to about $138 \mathrm{mg} \cdot \mathrm{m}^{-2} \cdot \mathrm{d}^{-1} ; r^{2}=0.99, P \leq 0.0021$ ). Thereafter, however, $\mathrm{CM}$ mass per unit area continuously decreased $\left(-20 \mathrm{mg} \cdot \mathrm{m}^{-2} \cdot \mathrm{d}^{-1} ; r^{2}=0.87, P \leq 0.0007\right)$, averaging $4.7 \mathrm{~g} \cdot \mathrm{m}^{-2}$ at $133 \mathrm{DAFB}$ (Fig. 2A). The initial increase (50 to 71 DAFB) was accounted for by both an increase in wax $\left(50 \mathrm{mg} \cdot \mathrm{m}^{-2} \cdot \mathrm{d}^{-1} ; r^{2}=0.96, P \leq 0.0188\right)$ and cutin deposition $\left(88 \mathrm{mg} \cdot \mathrm{m}^{-2} \cdot \mathrm{d}^{-1} ; r^{2}=0.99, P \leq 0.0048\right)$, and the net decrease thereafter (71 to $133 \mathrm{DAFB}$ ) by a continuing increase in wax deposition $\left(10 \mathrm{mg} \cdot \mathrm{m}^{-2} \cdot \mathrm{d}^{-1} ; r^{2}=0.83, P \leq 0.0015\right)$ and a simultaneous decrease in cutin deposition per unit area $\left(-30 \mathrm{mg} \cdot \mathrm{m}^{-2} \cdot \mathrm{d}^{-1} ; r^{2}=0.95, P \leq 0.0001\right)$.

There was little difference in CM mass per unit area between different regions of the fruit surface (Table 1). Assuming the

Table 1. Mass of the cuticular membrane (CM) per unit fruit surface area in selected regions of mature 'Valjevka' european plum.

\begin{tabular}{lc}
\hline Region & CM mass $\left[\right.$ mean $\left.\pm \mathrm{SE}\left(\mathrm{g} \cdot \mathrm{m}^{-2}\right)\right]$ \\
\hline Pedicel end & $4.67 \pm 0.04 \mathrm{c}^{\mathrm{z}}$ \\
Cheek & $4.86 \pm 0.03 \mathrm{bc}$ \\
Stylar end & $5.21 \pm 0.10 \mathrm{a}$ \\
Suture & $5.09 \pm 0.09 \mathrm{ab}$ \\
Grand mean & $4.96 \pm 0.06$
\end{tabular}

${ }^{\mathrm{z}}$ Mean separation by Tukey's studentized range test at $P \leq 0.05$. cheek region to be representative of the entire fruit surface, the amount of $\mathrm{CM}$ on a whole-fruit basis was calculated from $\mathrm{CM}$ mass in the cheek region and fruit surface area (Fig. 2B). These calculations revealed that $\mathrm{CM}$ mass per fruit increased rapid initially (up to 71 DAFB), but thereafter at a decreased rate. Up to $71 \mathrm{DAFB}$, the increase in CM mass was accounted for by both increased cutin and increased wax deposition. From 71 DAFB to maturity, the amount of cutin per fruit remained about constant, but wax deposition continued to increase.

Percentage strain of the CM decreased from $12.0 \%$ to $4.5 \%$ between 50 and 71 DAFB, but increased thereafter to about $40 \%$ at maturity (Fig. 3A). Qualitatively similar relationships were obtained when expressing $\mathrm{CM}$ strain as a function of surface area (Fig. 3A, inset). Plotting CM strain versus $\mathrm{CM}$ mass per unit area also revealed a biphasic relationship. The initial increase in CM mass per unit area (50 to $71 \mathrm{DAFB}$ ) was accompanied by decreasing strain of the CM. However, as CM mass per unit area decreased thereafter (71 and 133 DAFB), strain of $\mathrm{CM}$ increased (Fig. 3B). The breakpoint in this
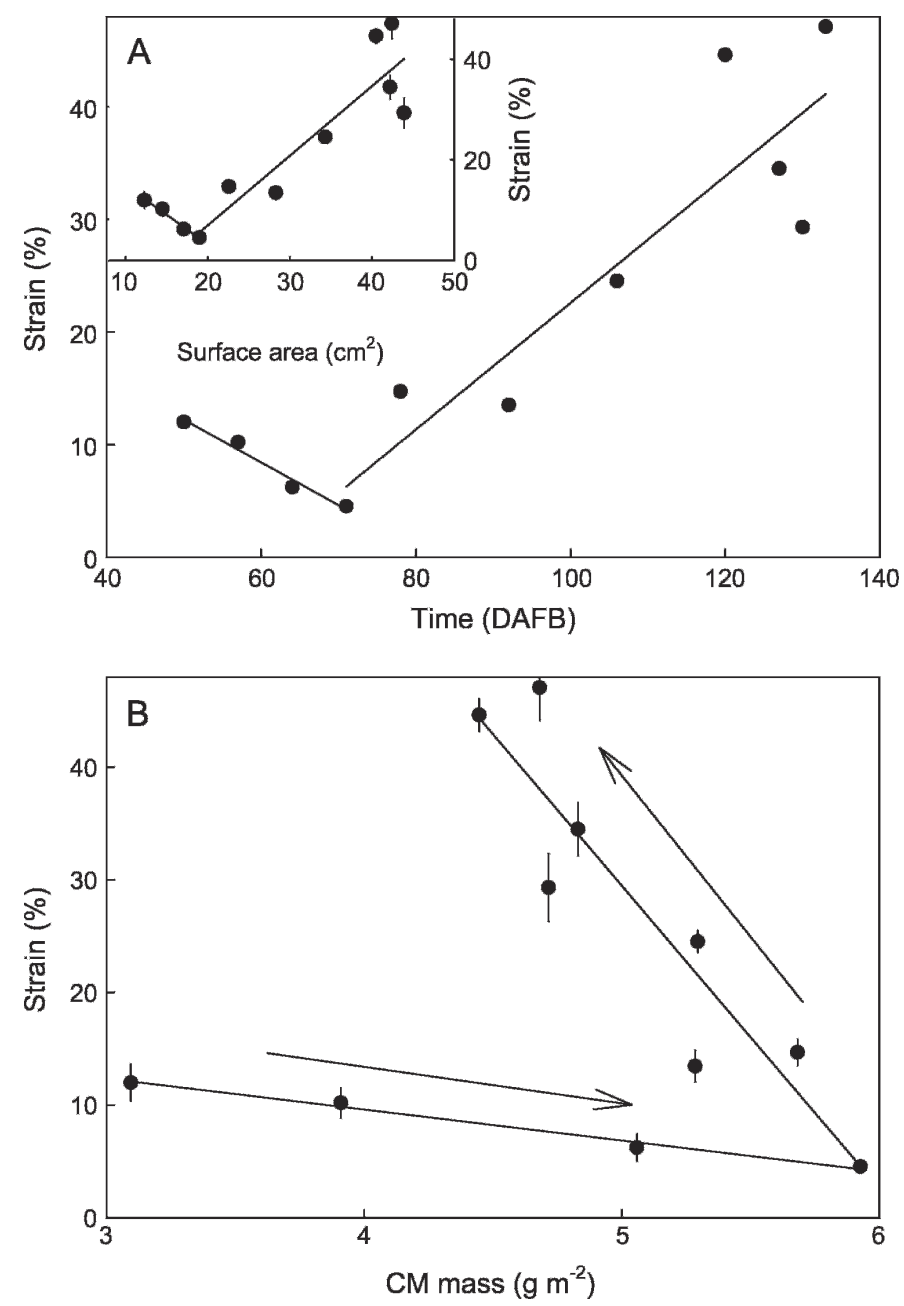

Fig. 3. (A) Time course of strain of the cuticular membrane (CM) of developing 'Valjevka' european plum. (A, inset) Strain as a function of fruit surface area. $\mathrm{X}$ - axis scale in days after full bloom (DAFB). (B) Strain as a function of CM mass per unit fruit surface area. Arrows indicate direction of change in $\mathrm{CM}$ mass per unit area during fruit development. The initial increase in CM mass per unit area up to 71 DAFB was followed by a subsequent decrease until maturity. 
relationship corresponded to the change in rate of cutin deposition at 71 DAFB (Fig. 2).

There was little microcracking of the CM up to 92 and 106 DAFB in pedicel end and cheek region respectively. Thereafter, however, microcracking markedly increased. Rating scores were always higher for the pedicel end than the cheek region (Fig. 4A). Plotting rating scores for microcracking in the cheek region versus strain of the $\mathrm{CM}$ in that region yielded a sigmoidal relationship across different developmental stages of 'Valjevka' fruit, but also across selected cultivars at maturity (Fig. 4B) that differed in CM mass per unit area, strain, and microcracking (Table 2). Up to $20 \%$ strain, there was little change in microcracking. However, above $20 \%$ strain, microcracking of the CM markedly increased (Fig. 4B). Most microcracks in the $\mathrm{CM}(91.0 \% \pm 3.7 \%$ at 133 DAFB) were associated with stomata. Typically, microcracks occurred first in the CM above the common periclinal cell wall of a pair of guard cells (Fig. 5A), subsequently extended along the long axis of the aperture of the stomatal apparatus tearing apart the guard cells (Fig. 5B), continuing above epidermal cells in the
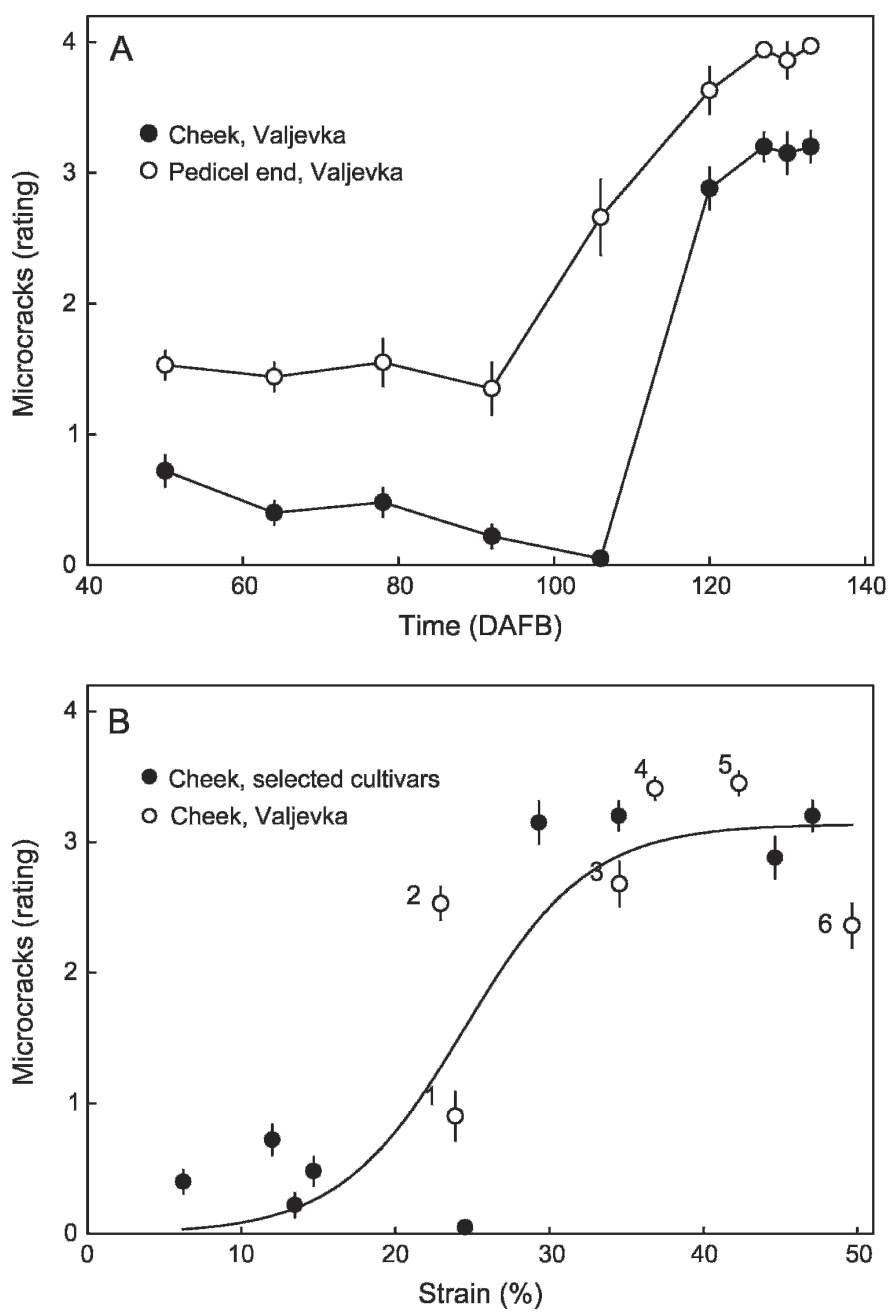

Fig. 4. (A) Time course of microcracking in cheek and pedicel end region of developing 'Valjevka' european plum. X-axis scale in days after full bloom (DAFB). (B) Microcracking in the cheek region as a function of strain of the cuticular membrane (CM) of developing 'Valjevka' and of selected european plum cultivars at maturity: 1, 'Elena'; 2, 'Auerbacher'; 3, 'President'; 4, 'Cacaks Fruchtbare'; 5, 'Valjevka'; and 6, 'Verity' (see Table 2). vicinity of the stomata apparatus (Fig. 5C), and finally merged with other microcracks, forming a network of longer and branched cracks (Fig. 5D). There was no evidence of microcracks extending into epidermal and hypodermal cell layers or the mesocarp.

\section{Discussion}

Our data established that cuticle deposition did not keep pace with fruit surface expansion in developing european plum. Furthermore, deposition of the two major CM constituentswax and cutin-differed. Up to about 71 DAFB, deposition of cutin and wax occurred concurrently, but thereafter deposition of cutin nearly ceased, resulting in a thinning of the cutin matrix on the enlarging fruit surface. In contrast, wax deposition continued at a constant rate until maturity. Because the cutin matrix is cross-linked and, therefore, largely responsible for the mechanical properties of the CM (Petracek and Bukovac, 1995), a close relationship between cutin deposition, fruit surface expansion, and strain was obtained. During early stage III (up to about 71 DAFB), cutin deposition was sufficiently high to prevent thinning and strain of the $\mathrm{CM}$ on the enlarging surface. However, when cutin deposition ceased around 71 DAFB, CM thickness decreased and strain of the CM increased as the fruit surface expanded. The increase in strain resulted in microcracking of the CM. Currently, it is not known why cutin deposition ceased, but wax deposition continued to occur throughout development.

CM deposition in developing european plum resembled that in sweet cherry in several aspects. First, CM deposition in both species did not keep pace with surface expansion. However, the pattern of cutin and wax deposition slightly differed. In plum, cutin deposition ceased not before mid stage III ( $>71$ DAFB), but ceased in sweet cherry as early as stage II (Peschel et al., 2007). Also in plum, wax deposition occurred throughout development, resulting in an increase in wax content from $20.9 \%$ to $48.7 \%$ between early stage III and maturity, whereas in sweet cherry wax content of the CM remained essentially constant throughout stage III [29.7\% vs. $30.5 \%$ for early stage III vs. maturity respectively (Knoche et al., 2001)]. To our knowledge, chemical analyses of wax and cutin fractions of the plum CM have not been published. For the sweet cherry CM, such analyses revealed that the change in amount of wax per fruit was the net effect of opposing processes (i.e., increasing alcohols and alkanes, but little change in triterpenes)(Peschel et al., 2007). Second, CMs of mature plum and sweet cherry fruit are markedly strained (Knoche et al., 2004). Percentage strain in european plum was lower than that reported for sweet cherry [ $40 \%$ vs. up to $100 \%$ and more for 'Valjevka' plum vs. 'Summit' sweet cherry respectively (Knoche and Peschel, 2006)]. Third, in both species the extent of microcracking increased toward maturity, when strain of the CMs was high. In european plum, the bimodal relationship between rating scores for microcracking and strain of the $\mathrm{CM}$ indicated that beyond a threshold of critical strain $\left(\varepsilon_{\text {crit }}\right)$ of about $20 \%$, microcracking markedly increased. Performing the same analysis in sweet cherry yielded a similar threshold for the relationship between microcracking and elastic strain of the CM in the cheek region (M. Knoche, unpublished data). Quantitatively, there was more microcracking (i.e., a higher frequency of fruit with microcracks or more severe microcracking in european plum 
Table 2. Properties of the fruit cuticular membrane $(\mathrm{CM})$ of selected cultivars of european plum at commercial maturity.

\begin{tabular}{lcccc}
\hline Cultivar & $\begin{array}{c}\text { Mass } \\
{[\text { mean } \pm \mathrm{SE}(\mathrm{g} \text { per fruit })]}\end{array}$ & $\begin{array}{c}\text { CM mass } \\
{\left[\text { mean } \pm \mathrm{SE}\left(\mathrm{g} \cdot \mathrm{m}^{-2}\right)\right]}\end{array}$ & $\begin{array}{c}\text { Strain } \\
{[\text { mean } \pm \mathrm{SE}(\%)]}\end{array}$ & $\begin{array}{c}\text { Microcracks } \\
{[\mathrm{mean} \pm \mathrm{SE}(\mathrm{rating})]}\end{array}$ \\
\hline Auerbacher & $24.1 \pm 0.6 \mathrm{~d}^{\mathrm{z}}$ & $5.59 \pm 0.05 \mathrm{~b}$ & $22.9 \pm 2.4 \mathrm{c}$ & $2.5 \pm 0.1 \mathrm{~b}$ \\
Cacaks Fruchtbare & $30.6 \pm 0.9 \mathrm{c}$ & $4.44 \pm 0.07 \mathrm{~d}$ & $36.8 \pm 1.5 \mathrm{~b}$ & $3.4 \pm 0.1 \mathrm{a}$ \\
Elena & $26.7 \pm 0.9 \mathrm{~cd}$ & $7.78 \pm 0.04 \mathrm{a}$ & $23.9 \pm 0.8 \mathrm{c}$ & $0.9 \pm 0.2 \mathrm{c}$ \\
President & $65.8 \pm 1.7 \mathrm{a}$ & $4.39 \pm 0.05 \mathrm{~d}$ & $34.5 \pm 1.9 \mathrm{~b}$ & $2.7 \pm 0.2 \mathrm{~b}$ \\
Valjevka & $38.7 \pm 0.9 \mathrm{~b}$ & $4.84 \pm 0.05 \mathrm{c}$ & $42.3 \pm 4.4 \mathrm{ab}$ & $3.5 \pm 0.1 \mathrm{a}$ \\
Verity & $41.3 \pm 1.1 \mathrm{~b}$ & $4.13 \pm 0.05 \mathrm{e}$ & $49.6 \pm 1.8 \mathrm{a}$ & $2.4 \pm 0.2 \mathrm{~b}$ \\
\hline
\end{tabular}

${ }^{\mathrm{z}}$ Mean separation within columns by Tukey's studentized range test at $P \leq 0.05$.

Cuticular mass (CM), strain, and microcracking were determined in the cheek region. For details on the rating scheme of microcracking, see Materials and Methods.

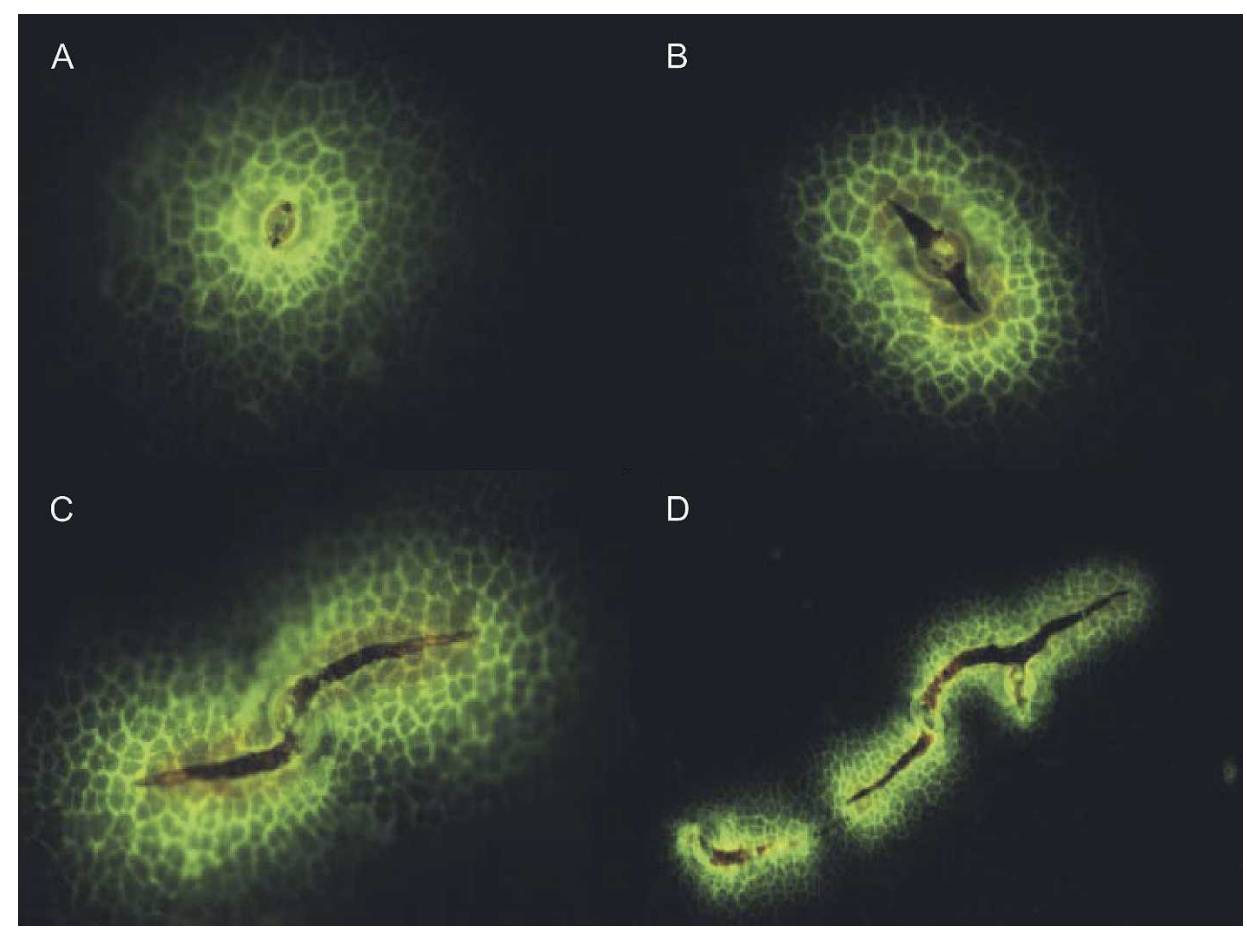

Fig. 5. (A-D) Fluorescence light micrographs of epidermal segments showing microcracks in the cuticle of 'Valjevka' european plum fruit. (A) Initiation of microcrack above common anticlinal wall of a pair of guard cells. Extending microcracks (B, C) that merge into larger, branched cracks involving several stomata (D). Magnification: $\times 200(\mathbf{A}-\mathbf{C}), \times 100(\mathbf{D})$

compared with sweet cherry) (Peschel and Knoche, 2005). The reason for these difference are unknown. In both species, more microcracking occurred in the pedicel end than in the cheek region (Peschel and Knoche, 2005). This would be expected because 1) the pedicel end region has a higher curvature than the cheek and 2) the strongest structure for a given "shell" morphology is the one with the least curvature (i.e., a perfect sphere) (Considine and Brown, 1981). Interestingly, in plum, essentially all microcracks were associated with stomata, confirming earlier observations by Mrozek and Burkhardt (1973) and Storey and Price (1999). In sweet cherry, however, microcracks were rarely associated with stomata and occurred mostly above periclinal cell walls of epidermal cells (Peschel and Knoche, 2005). Preferential formation of microcracks at lenticels was reported for grape [Vitis vinifera L. (Brown and Considine, 1982)]. Here, lenticels represented areas of limited extensibility in the extensible epidermis causing stress concentration and hence, crack formation in the vicinity of lenticels. In european plum, cell-tocell adhesion of guard cells represented the weakest link, because microcracks commenced at and extended along the length axis of the stomatal aperture (Fig. 5).

From a practical point of view, two questions arise: Are microcracks in the $\mathrm{CM}$ of developing fruit of european plum important? And, if so, what can be done to avoid microcracking? Microcracks impair the barrier function of the CM. In sweet cherry fruit, microcracks facilitate infection with fruit rot pathogens such as $B$. cinerea and M. laxa (Borve et al., 2000), allow rapid uptake of water and subsequent fruit cracking (Glenn and Poovaiah, 1989; Peschel and Knoche, 2005), and increase transpiration (Knoche et al., 2000). We expect similar relationships for european plum, for which Monilinia fruit rot and fruit cracking pose serious limitations to crop production, particularly during wet growing seasons. Also, russeting and russet scab of plum are likely to be related to microcracking of the $\mathrm{CM}$, possibly as a result of exposure of the fruit surface to liquid water or high concentrations of water vapor (Knoche and Peschel, 2006; Michailides, 1991). Furthermore, increased transpiration as a result of strain cracking of the CM may be involved in shriveling of the pedicel region of european plum, a disorder that regularly occurs in southern Germany. These arguments demonstrate that microcracking of the $\mathrm{CM}$ is important in european plum.

The data presented herein demonstrate that strain of the CM represents the driving force for microcracking and strain, in turn, results from a mismatch of fruit surface expansion and $\mathrm{CM}$ deposition. Strategies to avoid microcracking of the CM should therefore focus on synchronizing CM deposition and fruit surface expansion. Whether this can be achieved by breeding approaches or by cultural means [e.g., spray application of gibberellins on developing fruit as recently demonstrated in tomato (Lycopersicon esculentum Mill.)(Knoche and Peschel, 2007)] merits investigation. 


\section{Literature Cited}

Borve, J., L. Sekse, and A. Stensvand. 2000. Cuticular fractures promote postharvest fruit rot in sweet cherries. Plant Dis. 84:1180 1184.

Brown, K. and J. Considine. 1982. Physical aspects of fruit growth: Stress distribution around lenticels. Plant Physiol. 69:585-590.

Considine, J. and K. Brown. 1981. Physical aspects of fruit growth: Theoretical analysis of distribution of surface growth forces in fruit in relation to cracking and splitting. Plant Physiol. 68:371-376.

Glenn, G.M. and B.W. Poovaiah. 1989. Cuticular properties and postharvest calcium applications influence cracking of sweet cherries. J. Amer. Soc. Hort. Sci. 114:781-788.

Knoche, M., M. Beyer, S. Peschel, B. Oparlakov, and M.J. Bukovac. 2004. Changes in strain and deposition of cuticle in developing sweet cherry fruit. Physiol. Plant. 120:667-677.

Knoche, M. and S. Peschel. 2006. Water on the surface aggravates microscopic cracking of the sweet cherry fruit cuticle. J. Amer. Soc. Hort. Sci. 131:192-200.

Knoche, M. and S. Peschel. 2007. Gibberellins increase cuticle deposition in developing tomato fruit. Plant Growth Regul. 51: $1-10$.

Knoche, M., S. Peschel, M. Hinz, and M.J. Bukovac. 2000. Studies on water transport through the sweet cherry fruit surface: Characterizing conductance of the cuticular membrane using pericarp segments. Planta 212:127-135.

Knoche, M., S. Peschel, M. Hinz, and M.J. Bukovac. 2001. Studies on water transport through the sweet cherry fruit surface: II. Conductance of the cuticle in relation to fruit development. Planta 213:927936.

Lilleland, O. and L. Newsome. 1934. A growth study of the cherry fruit. Proc. Amer. Soc. Hort. Sci. 32:291-299.

Michailides, T.J. 1991. Russeting and russet scab of prune, an environmentally induced fruit disorder: Symptomatology, induction, and control. Plant Dis. 75:1114-1123.

Mrozek, R.F. and T.H. Burkhardt. 1973. Factors causing prune side cracking. Trans. Amer. Soc. Agr. Eng. 16:686-695.

Peschel, S., R. Franke, L. Schreiber, and M. Knoche. 2007. Composition of the cuticle of developing sweet cherry fruit. Phytochemistry 68:1017-1025.

Peschel, S. and M. Knoche. 2005. Characterization of microcracks in the cuticle of developing sweet cherry fruit. J. Amer. Soc. Hort. Sci. 130:487-495.

Petracek, P.D. and M.J. Bukovac. 1995. Rheological properties of enzymatically isolated tomato fruit cuticle. Plant Physiol. 109:675679.

Storey, R. and W.E. Price. 1999. Microstructure of the skin of d'Agen plums. Sci. Hort. 81:279-286. 